\title{
Effect of Micro Health Insurance on Access and Utilization of Health Services in Karnataka
}

\author{
S. Savitha*
}

School of Management, Manipal University, Manipal, Karnataka, India

\begin{abstract}
Background: Lack of sustainable and affordable health financing mechanisms in India has exposed the poor in informal sector to iatrogenic poverty. Hardship financing of health services has negative financial consequences on the future income of these households. This can be mitigated through micro health insurance (MHI) because it aims to remove financial barriers to access and utilize health services.

Objectives: Recognizing the dearth of studies on impact of MHI schemes in India, we carried out an in-depth study on Sampoorna Suraksha Programme (SSP) in Karnataka to assess the effect on access and utilization of healthcare services.

Methods: We designed a descriptive cross sectional household survey that collected data from 1146 households to evaluate the impact using logistic regression analysis.

Results: Insured individuals were more likely to access and utilize inpatient services compared to uninsured individuals. Moral hazard measured as length of stay in the hospital was absent. Horizontal equity in utilization based on gender and income was observed. Insured used private providers than public hospitals or self-medicine. The results of the study support the positive impact of MHI on access and utilization of health services.

Conclusion: The findings of the study enhance our understanding of the positive role of MHI in the promotion of better health behavior of the poor people who usually forego treatment during illness. This would reinforce policymakers to advocate MHI to mitigate iatrogenic poverty in India, the land of villages.
\end{abstract}

Keywords: Access, equity, health care financing, health seeking behavior, micro health insurance, utilization.

\section{INTRODUCTION}

Universal coverage of health services requires access to affordable treatment to the entire population. Health system performs health financing function to achieve universal coverage that ensures access, regardless of one's ability to pay [1]. Financing health expenses have been a difficult task for the poor households in India due to lack of adequate health financing mechanisms. It is disheartening to note that health spending by the government is just $1.17 \%$ of GDP, which is very low compared to other countries [2]. Further, the quality of services at government hospitals is inadequate $[3,4]$. People rely on unregulated high cost private providers that have resulted in massive out of pocket expenses $(91.8 \%$ of private health expenditure) and impoverishment [2]. The poorest are 2.6 times more likely to forgo health services than the richest and one quarter of Indians seeking inpatient care falls below the poverty line [5]. In Karnataka, $17 \%$ of people do not seek care despite illness, mainly due to financial barriers [6]. These financial barriers, giving rise to high latent demand and under-utilization of health services can be overcome through health insurance schemes, either social or private health insurance. Then again, large proportion of Indian population lives in informal sector that is deprived of less expensive yet comprehensive social health

*Address correspondence to this author at the School of Management, Manipal University, Manipal, Karnataka, India; Tel: 00919448103447; E-mail: bsbasri@gmail.com insurance coverage. Health insurance schemes of private companies are expensive with high transaction costs. Subsequently, micro health insurance (MHI) is emphasized as a viable option to protect the poor from iatrogenic poverty. MHI is any not-for-profit insurance scheme aimed primarily at the informal sector that practices collective pooling of health risks [7]. The insured can get cashless treatment or reimbursement from insurance companies; hence it differs from out of pocket payments incurred during emergency.

Theoretically, any price decrease through insurance claim should enhance the utilization. Since MHI brings down the price of health care, there would be better access to modern/ formal health facilities and higher consumption of health services by insured individuals. Thus, MHI provides equitable access to health facilities, irrespective of income and gender while reducing financial burden of illness. Potential positive benefits of MHI are appealing; however empirical studies are yet to prove these benefits. Existing literature provides conflicting evidence on the impact of MHI on access to care, health seeking behaviour (HSB) and utilization of health services. Some of the studies carried out in Tanzania [8], Senegal [9] and China [10] document higher access to curative care whereas others claim increased utilization of health services [2, 9, 11-14]. Several studies are less optimistic and prove the absence of positive impact on utilization [10, 15-19]. Further, a desirable effect on HSB is evident from some studies which report insured seeking care 
at visit official channels rather than self-care or unofficial channels [19-22]. As against this finding, Jowett concludes minimal effect in Senegal [23]. Some authors claim income to be a major barrier to access care that prevents low-income people from seeking care [24]. Evidence on the impact of MHI in India is lacking and available literature provides inconclusive evidence. This study adds to the limited evidence by evaluating the Sampoorna Suraksha Programme (SSP), a well-known MHI scheme in Karnataka. We use mupliple regression analysis of household survey data to answer three questions. First, we seek to assess MHI impact on access health care: Does MHI improve on access to care for insured individuals? Secondly, we examine the HSB of insured individuals: Do insured individuals seek care at formal providers of health care compared with uninsured? Thirdly, we evaluate the probability of utilization of inpatient services: Does MHI increase utilization of inpatient services?

\section{STUDY SETTING}

The Sampoorna Suraksha Programme is the initiative of SKDRDP (Shree Kshetra Dharmasthala Rural Development Project), a non-governmental organization working for the overall development of poor people in Karnataka. SSP enables financial coverage to the self-help group (SHG) members of SKDRDP during illness through cashless treatment at 110 network hospitals. The four public sector insurance companies in India offer group health insurance policies through SSP that assumes the role of agent or insurance intermediary and uses existing infrastructure as well as established channels of micro-credit and microsavings to offer insurance products. Enrolment of members takes place in the month of February every year. The membership is voluntary and the premium is a uniform amount with no concession to low-income households. Hence, the poorest households have to incur a higher premium as a percentage of annual income compared to better-off households. The premium payable for the first member of a family is ₹ 250 in 2014-15 and inpatient health benefits are provided up to the sum assured of 10,000 per individual ( $₹ 50,000$ on a family floater basis). The premium is $1.17 \%$ of annual income of the households; it is the highest for low-income families (1.51\%).

The insurance package covers pre-existing diseases without waiting period restrictions, co-payments or deductibles. In 2013-14, SSP enrolled 13 lakh members and premium amount mobilized was ₹ 44.18 crore. A total of 36.44 crore were disbursed as claim benefits in the same year. Except 2013-14, SSP has incurred loss since inception due to insufficient premium collection and high level of claims. The number of enrolled members increased by $42.7 \%$ in the second year of operation (2005-06), by $90 \%$ in the third year (2006-07), but the growth was slower in the later years till 2010-11. Another observation is the higher level of claims ratio (208\%) in 2004-05, that reduced significantly (113\%) in 2007-08. However, it deteriorated to an alarming level of $197.5 \%$ in $2009-10$. On an average, the claims ratio is $107.5 \%$ in the last six years. The deficit in premium collection is absorbed by insurance companies that provide medical risk coverage.
The claim benefits from SSP would reduce the treatment cost for insured individuals that removes financial barrier to access health care. This would enhance equitable utilization of health services at private network hospitals, known for good quality of services in India. Hence, we hypothesize that insured individuals access care especially at private facilities and use inpatient services more than uninsured and newly insured individuals. There would be equity in health care utilization since vulnerable insured groups (women and poor) would increase the use of health services due to insurance. In this paper, we define equitable utilization as follows; vertical equity is the distribution of benefits across groups of people differing in socio-economic status (difference in income class in insured group) and horizontal equity is the distribution of benefits across groups of people of similar socio-economic status (difference in income class in insured and uninsured group) [16].

\section{MATERIALS AND METHODOLOGY}

The analysis presented in this paper are based on the data collected from a household survey that was carried out in the first half of the year 2011 in Karnataka State, South India. Pre-tested questionnaire elucidated information on the basic demographic and socio-economic characteristics of the households, incidence of illness and subsequent choice of health providers and type of treatment taken for the illness. The recall period was one year for hospitalization and three months for outpatient treatment. Households were classified into five income quintiles. The per capita annual income was categorized into five equal parts, after arranging them in an ascending order as; quintile 1(first 20\%), quintile 2 (next $20 \%$ ), quintile 3 (next 20\%), quintile 4 (subsequent $20 \%$ ) and quintile 5 (last $20 \%$ ).

Households were classified into three types of SSP membership categories: insured (who renewed their membership in the year 2011-12), newly insured (who enrolled for the first time in the year 2011-12) and uninsured households. Any study on impact evaluation suffers from endogeneity bias and misconstrues results. Hence, these three groups were selected in that insured and newly insured would have similar unobservable time in-variant characteristics since they self-select into the programme. Being members of SHGs, all these groups would have homogeneous characteristics. This design would reduce endogeneity bias to a large extent. In addition, Durbin-WuHausman test was carried out to test endogeneity [18].

Multistage cluster sampling method was adopted to select the households for the survey. The sample was selected in five stages. In the first stage, three districts namely Dakshina Kananda, Uttara Kannada and Gadag and then ten taluks (administrative divisions) from these three districts were randomly selected. In the third and fourth stage, 18 valayas (region) (1-2 per taluk) from ten taluks and later from each valaya four to five karyakshetras (cluster of villages) were randomly selected. By using the list of SHG members available at the taluk project office, required number of insured, newly insured and uninsured households were selected. Sample size was 416 renewed insured, 366 newly insured and 364 uninsured households (target population was $8,92,740$ households, confidence interval of $5 \%$ and confidence level of $95 \%$ ). The data was coded and statistical 
analysis was carried out using International Business Machines (IBM) Inc. Statistical Package for the Social Sciences (SPSS) version 17.0 software.

\section{ECONOMETRIC MODELS}

Two econometric models are used to estimate probability of access to health services (model 1) and probability of hospitalization (models 2, 3, 3a and 3b).

Prob (access to care $>0 \mid$ ill $)=\beta_{0}+\beta_{1} \mathrm{M}_{\mathrm{x}}+\beta_{2} \mathrm{X}_{\mathrm{y}+} \varepsilon$

$\{1$ if access to care $>0,0$ otherwise $\}$

Prob (access to care $>0$ ill) is the probability of accessing formal care upon illness. $\mathrm{X}_{\mathrm{y}}$ is a set of predisposing, enabling and need variables that influence probability of hospitalization;

$\mathrm{M}_{\mathrm{x}}$ represents the mode of payment (SSP).

In addition, probability of hospitalization is analyzed to assess the impact of SSP on insured individuals.

Prob (hospitalization $>0 \mid$ ill) $=\beta_{0}+\beta_{1} M_{x}+\beta_{2} X_{y+} \varepsilon$

$\{1$ if hospitalization $>0,0$ otherwise $\}$

Prob (hospitalization $>0 \mid$ ill) is the probability of hospitalization upon illness. Certain independent variables are included in the analysis [25]. These are enabling (income quintile, job and education of heads of the households, area and district of residence), pre-disposing (gender and age of ill persons and size of household) and need factors (presence of chronic illness in the family in model 2 and types of illness in models $3,3 \mathrm{a}, 3 \mathrm{~b}$ ). Area of residence dummies is included to control unobservable characteristics of the communities. Model 2 considered total sample to control for sample selection bias. Model specifications are changed to substantiate the findings by considering the cases of individuals with illness (model 3), poor households (model 3a) and women (model 3b). Discriminant analysis is carried out to assess health seeking behaviour.

\section{RESULTS}

\section{Description of the Sample}

The survey sample included 1146 households in 84 villages. Descriptive statistics of the households (Table 1) shows the mean age of heads of the households to be 48 years for insured and uninsured and 47 years for newly insured group $(\mathrm{p}>0.05)$. Insured and uninsured households $(2.3 \mathrm{~km}$ and $2.4 \mathrm{~km}$ respectively) resided near the hospital compared to newly insured $(3.3 \mathrm{Km})(\mathrm{p}<0.05)$. Heads of insured households were predominantly male $(83.7 \%)$ and married $(86.5 \%)$ compared to uninsured $(79.9 \%$ and $81 \%$ respectively) and newly insured $(84.7 \%$ and $85 \%$ respectively) households.

\section{Access to Health Care Services}

The households reported incidences of more than one family member being sick. Hence, individual was taken as the unit of analysis. In the sample of 4961 individuals, we found 371 individuals suffering from the illness. Of them, 24
Table 1. Socio-economic characteristic of sample households.

\begin{tabular}{|c|c|c|c|}
\hline & Insured & Newly Insured & Uninsured \\
\hline \multicolumn{4}{|c|}{ Occupation of Head of the Household (\%) } \\
\hline Unskilled labour & 38.2 & 43.4 & 43.1 \\
\hline Skilled labour & 18 & 16.9 & 15.7 \\
\hline Self-employment & 10 & 5.4 & 8.5 \\
\hline Formal sector employment & 2.9 & 5.2 & 5.8 \\
\hline Unemployed & 12.3 & 12.8 & 10.7 \\
\hline Unskilled salaried (informal sector) & 5.8 & 5.2 & 5.2 \\
\hline Skilled salaried (informal sector) & 3.1 & 2.2 & 3.6 \\
\hline Agriculture & 3.6 & 3.8 & 2.5 \\
\hline \multicolumn{4}{|l|}{ Income Quintile (\%) } \\
\hline $\mathrm{Q} 1<₹ 14100$ & 18.5 & 20.5 & 22 \\
\hline Q2 ₹14101-₹19010 & 20.9 & 20.5 & 22 \\
\hline Q3 ₹19011- ₹24000 & 19 & 22 & 18.4 \\
\hline Q4 ₹24001-₹34800 & 21.9 & 21.3 & 22.3 \\
\hline Q5 >₹ 34800 & 19.7 & 15.6 & 17.6 \\
\hline \multicolumn{4}{|l|}{ Area of Residence } \\
\hline Rural & 52.2 & 55.2 & 56.2 \\
\hline Urban & 7.2 & 14.2 & 12.1 \\
\hline Semi Urban & 40.6 & 30.6 & 31.7 \\
\hline
\end{tabular}

individuals did not seek treatment from formal providers of care. A higher proportion of insured individuals $(96.8 \%)$ sought health services compared to uninsured $(87.2 \%)$ and newly insured group $(92.9 \%)$. There was no difference in access to care by gender. The mean distance to hospital is 2.9 $\mathrm{km}$ for those who did not seek care and $2.6 \mathrm{~km}$ for those who accessed care $(\mathrm{p}>0.05)$ (Table 2$)$.

Table 3 depicts the results of binary logistic regression analysis on the probability of access to health services (model 1). It shows that uninsured individuals were 0.3 times less likely to get formal treatment compared to insured individuals. Individuals living in semi urban areas were 0.245 times less likely to seek care compared to those in rural areas. Durbin-Wu-Hausman test suggests exogeneity with $\operatorname{prob}\left(\chi^{2}\right)=0.436$. The model predicts $93.3 \%$ of cases correctly.

Resource poor individuals borrowed to finance the medical expenses and a lower proportion of insured $(57.7 \%)$ borrow compared $78.4 \%$ of newly insured and $70.9 \%$ of uninsured individuals $(\mathrm{p}<0.05)$. Low income class individuals (Q1 to Q3) borrowed more than higher income class (Q5).

\section{Health Seeking Behaviour}

When we analyzed HSB of 361 individuals seeking remedy for illness, we observed 19 individuals resorting to 
Table 2. Description of variables: access to care on illness.

\begin{tabular}{|c|c|c|}
\hline & \multicolumn{2}{|c|}{ Access to Care } \\
\hline & $\begin{array}{c}\text { No } \\
(\mathrm{N}=\mathbf{2 4})\end{array}$ & $\begin{array}{c}\text { Yes } \\
(\mathbf{N}=332)\end{array}$ \\
\hline \multicolumn{3}{|l|}{ Health Insurance Status (\%) ${ }^{1^{*}}$} \\
\hline Insured & 20.8 & 45.8 \\
\hline Newly insured & 33.3 & 31.6 \\
\hline Uninsured & 45.8 & 22.6 \\
\hline Gender of Ill Person; Male $(\%)^{1}$ & 45.8 & 52.4 \\
\hline \multicolumn{3}{|l|}{ Type of Illness $(\%)^{1}$} \\
\hline Acute & 58.3 & 47 \\
\hline Chronic & 41.7 & 53 \\
\hline Age of Ill Person (Mean in Years) ${ }^{2}$ & 41 & 41 \\
\hline \multicolumn{3}{|l|}{ Income Quintile (\%) ${ }^{1}$} \\
\hline Q1 & 12.5 & 24.4 \\
\hline Q2 & 20.8 & 23.2 \\
\hline Q3 & 29.2 & 20.8 \\
\hline Q4 & 29.2 & 17.5 \\
\hline Q5 & 8.3 & 14.2 \\
\hline Distance of Hospital (Mean in km) ${ }^{2}$ & 2.9 & 2.6 \\
\hline \multicolumn{3}{|l|}{ Area of Residence $(\%)^{1^{*}}$} \\
\hline Urban & 45.8 & 12.7 \\
\hline Semi urban & 16.7 & 37 \\
\hline Rural & 37.5 & 50.3 \\
\hline
\end{tabular}

${ }^{1}$ Chi square test value.

${ }^{2}$ Mann Whitney $U$ test $p$ value.

${ }^{*} \mathrm{p}<0.05$.

self-treatment and a large number of (342) individuals using formal treatment. Out of the total 440 visits, 37 were made to public hospitals, 384 to private facilities and the remaining to traditional medicine (Ayurveda and homeopathy). A higher percentage of insured individuals sought care from private hospitals (district and regional) and nursing homes compared to uninsured and newly insured individuals (Table 4).

Discriminant analysis enables a better understanding of the selection of providers. Structure matrix was obtained by including insured and newly insured/ uninsured as grouping variable and home medicine, clinic, government hospitals, district hospitals, regional hospitals, and nursing homes as predictor variables. Visits to clinics (0.703), government hospitals (0.321) and home medicine (0. 414) and not accessing care at district hospitals (-0.462) differentiate newly insured from insured individuals. Visits to government hospitals (-0.528), home medicine (-0.614) and regional hospitals $(0.446)$ differentiate insured from uninsured individuals.

\section{Utilization of Health Care Services}

Utilization of inpatient health services was high in the insured group (50\%) compared to newly insured $(28.7 \%)$ and uninsured group $(21 \%)(\mathrm{p}=0.00)$. Overall, regardless of insurance, majority of ill persons availed inpatient services $(76.8 \%)$ than outpatient treatment $(20.5 \%)$. Since higher hospitalization was reported by insured group, despite homogeneity in the type of illness among the three groups, question of moral hazard arises. Hence, we compared the number of days spent in the hospital to check for overutilization by insured individuals. Even though insured spent longer days in the hospital (19 days) than newly insured (15 days) and uninsured individuals (12 days), it is statistically insignificant suggesting no moral hazard in SSP $(\mathrm{p}>0.05)$.

Table 3. Estimation of model 1: probability of access to care.

\begin{tabular}{|l|c|c|c|c|}
\hline & $\operatorname{Exp(B)}$ & Sig. & \multicolumn{2}{|c|}{$\begin{array}{c}\text { 95\% C.I. for Exp (B) } \\
\text { Lower Upper }\end{array}$} \\
\hline \hline Health insurance (base: Insured) & & 0.107 & & \\
\hline Newly insured & 0.581 & 0.376 & 0.175 & 1.935 \\
\hline Uninsured & 0.300 & 0.039 & 0.096 & 0.940 \\
\hline Type of illness (base: Acute) Chronic & 1.704 & 0.258 & 0.677 & 4.286 \\
\hline Age of ill person & 0.997 & 0.861 & 0.970 & 1.026 \\
\hline Gender of ill person & 0.719 & 0.475 & 0.291 & 1.777 \\
\hline Distance to hospital & 0.944 & 0.532 & 0.786 & 1.132 \\
\hline Area of residence (base: Rural) & & 0.004 & & \\
\hline Urban & 0.245 & 0.007 & 0.088 & 0.681 \\
\hline Semi urban & 1.573 & 0.476 & 0.453 & 5.453 \\
\hline Income quintile (base: Q5) & & 0.666 & & \\
\hline Q1 & 1.300 & 0.789 & 0.191 & 8.847 \\
\hline Q2 & 0.618 & 0.591 & 0.107 & 3.579 \\
\hline Q3 & 0.584 & 0.543 & 0.103 & 3.310 \\
\hline Q4 & 0.458 & 0.369 & 0.083 & 2.519 \\
\hline Constant & 55.834 & 0.000 & & \\
\hline Number of observations & 357 & & & \\
\hline
\end{tabular}

Omnibus test model coefficient: Pearson chi square $=25.025, \mathrm{p}=0.015 ;-2 \log$ likelihood=150.770; Hosmer and Lemeshow Pearson chi square $=6.669, \mathrm{p}=0.573$. (Dependent variable: Access to care; $1=$ yes).

Table 4. Health seeking behaviour in the first visit.

\begin{tabular}{|l|c|c|c|}
\hline & Insured & Newly Insured & Uninsured \\
\hline \hline Home medicine (N=19) & 21.1 & 26.3 & 52.6 \\
\hline Clinic (N=64) & 34.4 & 42.2 & 23.4 \\
\hline Nursing home (N=18) & 55.6 & 38.9 & 5.5 \\
\hline Government hospital (N=31) & 29 & 35.5 & 35.5 \\
\hline District hospital (N=118) & 51.6 & 29.7 & 18.7 \\
\hline Regional hospital $(\mathrm{N}=108)$ & 49.1 & 29.6 & 21.3 \\
\hline Ayurvedic hospital $(\mathrm{N}=5)$ & 20 & 40 & 40 \\
\hline
\end{tabular}

$\chi^{2}(12, \mathrm{~N}=361)=21.705, \mathrm{p}=0.041$ (Figures are $\%$ ages to total of each row).

Besides, our analysis suggests higher hospitalization among insured women $(86.7 \%)$ compared to uninsured women $(62 \%)$ and newly insured women $(58.5 \%)(\mathrm{p}<0.05)$. This means SSP ensures horizontal equity in utilization, based on gender. Likewise horizontal equity based on income is evident since insured poorer members (Q1 and Q2 
income quintile) were hospitalized in a higher proportion $(93.1 \%)$ than those in uninsured $(64.3 \%)$ and newly insured groups $(76 \%)(\mathrm{p}=0.001)$. Among hospitalized individuals, chronic illness was observed in insured and uninsured group (Table 5).

Table 5. Description of independent variables: utilization of health services.

\begin{tabular}{|c|c|c|c|}
\hline & $\begin{array}{l}\text { Insured } \\
(\mathrm{N}=140)\end{array}$ & $\begin{array}{l}\text { Newly Insured } \\
\quad(\mathbf{N}=75)\end{array}$ & $\begin{array}{c}\text { Uninsured } \\
(\mathbf{N}=57)\end{array}$ \\
\hline \multicolumn{4}{|l|}{ Type of Illness ${ }^{1}$} \\
\hline Acute illness & 43.5 & 49.2 & 45.6 \\
\hline Chronic illness & 54 & 45 & 50 \\
\hline Maternity care & 2.5 & 5.8 & 4.4 \\
\hline $\begin{array}{l}\text { Gender of ill person }{ }^{1} \\
\text { Male }\end{array}$ & 53.6 & 58.7 & 57.9 \\
\hline \multicolumn{4}{|c|}{ Job Status of Head of Household ${ }^{1}$} \\
\hline Unemployment & 13.5 & 10.7 & 14.1 \\
\hline Labourer & 57.4 & 66.9 & 57.6 \\
\hline Self employed & 11.5 & 5.4 & 11.7 \\
\hline Agriculture & 6.1 & 4.4 & 2.3 \\
\hline Formal sector & 6.1 & 6.3 & 7.1 \\
\hline Salaried (informal sector) & 5.4 & 6.3 & 7.2 \\
\hline \multicolumn{4}{|l|}{ Income Class $^{1}$} \\
\hline Q1 & 21.7 & 23.3 & 25.6 \\
\hline Q2 & 24.2 & 20 & 24.4 \\
\hline Q3 & 23 & 20 & 18.9 \\
\hline Q4 & 14.9 & 22.5 & 17.8 \\
\hline Q5 & 16.2 & 14.2 & 13.3 \\
\hline \multicolumn{4}{|l|}{ Area of Residence ${ }^{1^{*}}$} \\
\hline Urban & 7.9 & 14.7 & 21.4 \\
\hline Semi-urban & 40.3 & 38.7 & 26.8 \\
\hline Rural & 51.8 & 46.6 & 51.8 \\
\hline
\end{tabular}

Chi square test.

$* \mathrm{p}<0.1$.

Binary logistic regression analysis shows the probability of hospitalization (Table 6). In model 2, newly insured were 0.577 times less likely and uninsured were 0.409 times less likely to get admission compared to insured (Table 6). Households with chronically ill members were 4.877 times more likely to report hospitalization compared to households without chronic illness. The model correctly predicts $77.8 \%$ of the cases. The endogeneity test using Durbin-WuHausman test supports exogeneity of health insurance (model 2) with prob $\left(\mathrm{chi}^{2}\right)=0.793$.

Model 3 (sample of ill persons) depicts a similar picture with lower odds of hospitalization for newly insured (odds ratio 0.271 ) and uninsured (odds ratio 0.243) individuals compared with insured (Table 7). Men were 2.164 times more likely to have hospitalization than women. Chronically ill Individuals were 2.034 times more likely to get admission compared to individuals with acute illness. Individuals from Q4 (odds ratio 0.291 ) income quintile were less likely to have hospitalization compared to high income quintile (Q5) individuals. The model correctly predicts $77.7 \%$ of the cases.

Table 6. Probability of hospitalization: results of models $2 \& 3$.

\begin{tabular}{|c|c|c|c|c|}
\hline & $\begin{array}{l}\text { Model } 2 \\
\text { Exp (B) }\end{array}$ & Sig. & $\begin{array}{l}\text { Model } 3 \\
\text { Exp (B) }\end{array}$ & Sig. \\
\hline Health insurance (base: Insured) & & 0.000 & & 0.000 \\
\hline Newly insured & 0.577 & 0.003 & 0.271 & 0.000 \\
\hline Uninsured & 0.409 & 0.000 & 0.243 & 0.000 \\
\hline $\begin{array}{l}\text { Chronic illness in the family } \\
\text { (base: No) }\end{array}$ & 4.877 & 0.000 & - & - \\
\hline $\begin{array}{l}\text { Gender of ill person } \\
\text { (base=Female) Male }\end{array}$ & - & - & 2.164 & 0.007 \\
\hline $\begin{array}{l}\text { Types of illness of sick } \\
\text { individual (base: Acute) Chronic }\end{array}$ & - & - & 2.034 & 0.013 \\
\hline Education of head (base: Illiterate) & & 0.082 & & 0.122 \\
\hline Primary (1-7) & 0.849 & 0.717 & 0.273 & 0.279 \\
\hline Secondary $(8-12)$ & 1.420 & 0.404 & 0.593 & 0.658 \\
\hline Graduate and above & 1.109 & 0.804 & 0.350 & 0.365 \\
\hline Job status (base: Unemployed) & & 0.786 & & 0.599 \\
\hline Labourer & 0.930 & 0.773 & 1.336 & 0.448 \\
\hline Self employed & 1.440 & 0.300 & 0.588 & 0.477 \\
\hline Agriculture & 1.383 & 0.496 & 2.223 & 0.244 \\
\hline Salaried in informal sector & 1.046 & 0.903 & 2.120 & 0.259 \\
\hline Formal sector & 1.116 & 0.806 & 2.194 & 0.343 \\
\hline Income quintile (base: Q5) & & 0.281 & & 0.257 \\
\hline Q1 & 1.289 & 0.341 & 0.371 & 0.093 \\
\hline Q2 & 1.316 & 0.276 & 0.467 & 0.199 \\
\hline Q3 & 1.079 & 0.762 & 0.329 & 0.053 \\
\hline Q4 & 0.810 & 0.394 & 0.291 & 0.032 \\
\hline Household size (base 1-3) & & 0.361 & & 0.702 \\
\hline $4-6$ & 0.983 & 0.923 & 1.216 & 0.725 \\
\hline 7 and above & 1.465 & 0.220 & 1.443 & 0.473 \\
\hline Distance to hospital & 1.045 & 0.199 & 1.057 & 0.113 \\
\hline Area of residence (base: Rural) & & 0.174 & & 0.420 \\
\hline Urban & 1.425 & 0.090 & 0.706 & 0.384 \\
\hline Semi urban & 1.529 & 0.202 & 1.234 & 0.523 \\
\hline Constant & 1.23 & 0.510 & 12.28 & 0.054 \\
\hline Number of observations & 1146 & & 371 & \\
\hline
\end{tabular}

Omnibus test model coefficient: Model 2=174, p=0.00; Model 3=55.57, p=0.00; -2 log likelihood; Model 2=1107.79; Model 3=339; Hosmer and Lemeshow chi square; Model 2=1.955, $\mathrm{p}=0.982 ;$ Model 3=1.775, $\mathrm{p}=0.988$ (Dependent variable: Hospitalization; 1=yes).

The cases of poor persons and ill women were considered to substantiate the findings of the above models (model 3a and $3 \mathrm{~b}$ ). As shown in Table 7 , model $3 \mathrm{a}$ predicts less likelihood of admission for newly insured and uninsured. 
Newly insured were 0.212 times less likely and uninsured were 0.173 times less likely to have admission compared to insured individuals. The odds of the admission was high for male (odds ratio 2.658) than female. The results of these tests show $78.9 \%$ of cases are correctly predicted by the model.

Table 7. Probability of hospitalization: results of model 3a and $3 \mathrm{~b}$.

\begin{tabular}{|c|c|c|c|c|}
\hline & $\begin{array}{l}\text { Model 3a } \\
\text { Exp (B) }\end{array}$ & Sig. & $\begin{array}{l}\text { Model 3b } \\
\text { Exp (B) }\end{array}$ & Sig. \\
\hline $\begin{array}{l}\text { Health insurance } \\
\text { (base=SSP insured) }\end{array}$ & & 0.002 & & 0.004 \\
\hline Newly insured & 0.212 & 0.004 & 0.277 & 0.004 \\
\hline Uninsured & 0.173 & 0.001 & 0.249 & 0.003 \\
\hline $\begin{array}{l}\text { Gender of ill person } \\
\text { (base=Female) Male }\end{array}$ & 2.658 & 0.018 & - & - \\
\hline $\begin{array}{l}\text { Types of illness } \\
\text { (base: Acute) Chronic }\end{array}$ & 1.599 & 0.256 & 1.611 & 0.197 \\
\hline Income quintile (base=Q5) & - & - & & 0.619 \\
\hline Q1 & - & - & 0.288 & 0.144 \\
\hline Q2 & - & - & 0.519 & 0.450 \\
\hline Q3 & - & - & 0.417 & 0.307 \\
\hline Q4 & - & - & 0.392 & 0.286 \\
\hline $\begin{array}{l}\text { Area of residence } \\
\text { (base=Rural area) }\end{array}$ & & 0.312 & & 0.127 \\
\hline Urban & 0.621 & 0.425 & 0.359 & 0.043 \\
\hline Semi-urban & 1.595 & 0.330 & 0.685 & 0.361 \\
\hline Constant & 3.439 & 0.052 & 13.536 & 0.002 \\
\hline Number of observations & 166 & & 171 & \\
\hline
\end{tabular}

In model 3b, newly insured (odds ratio 0.277) and uninsured (odds ratio 0.249) women have lower likelihood of hospitalization than insured women (Table 7). The model correctly predicts $76.9 \%$ of the cases.

Thus, men use inpatient services more than women in insured as well as uninsured/newly insured group. This prompts further analysis to assess barriers in utilization for women. In the insured group, heads of the households (39\%) and male members $(27 \%)$ decided the amount and items on which the family income has to be spent while women had minimal role to play (3\%). Even the decision to seek care was taken by the heads of the households $(43.5 \%)$ and male members (21\%). Similar intra-household dynamics was observed in uninsured and newly insured group. Likewise, our finding that the poorest use less health services compared with better-off in the insured group triggers further analysis. A large number of the poorest (83\%) borrowed to pay the premium to SSP and nearly one third of heads of these households worked as daily labourers. Almost $60 \%$ of them lived in rural areas that lack access to good hospitals and adequate transportation facilities.

\section{DISCUSSION}

Universal equitable access to health services is a health policy goal. The importance of MHI as a policy tool to eliminate financial barriers to access and utilize health services is being increasingly emphasized. In the backdrop of limited studies on this aspect, the current study examined the extent to which SSP, a MHI scheme targeted at the poor in Karnataka, provides equitable access and utilization of health care. We applied quantitative techniques to individuals' level survey data to test the hypothesis of better access to care, health seeking behaviour at formal health facilities and higher utilization of health services for insured individuals compared to uninsured and newly insured individuals.

The study highlights four noteworthy findings. Firstly, SSP has positive impact on access to care and secondly, insured seek treatment from private providers than public hospitals or home medicine. Thirdly, insured get hospitalized in higher proportion compared to uninsured and newly insured group and fourthly, horizontal equity based on income and gender exists.

We found strong evidence that SSP increases the likelihood of access to care compared with uninsured individuals (model 1). In contrast to this finding, we noted no difference in access to care among insured and newly insured group. The latter borrowed for treatment which compensated the lack of health insurance policy. Hence, equivocal impact is observed in this study. Further, we found a disparity in HSB among the studied groups that confirms SSP benefits. Insured individuals made more visits to private hospitals than public providers or home medicine compared to uninsured and newly insured groups. A desirable change in HSB can be attributed to certain design features of the programme that ensures good quality of care at lower cost. SSP insists on acceptable quality of services in its contract with network hospitals. Moreover, financial barriers to seek care at these hospitals are brought down due to risk coverage by SSP that makes health care affordable. There are a large number of network hospitals that increases accessibility. Thus, our study findings reinforce the positive findings of other studies conducted in different settings $[10,19,21,22]$ on HSB.

Our finding that SSP membership is associated with higher likelihood of utilization leads us to confidently conclude that SSP does increase the utilization of health services (models 2, 3, 3a and 3b). By removing financial barriers to hospitalization, SSP facilitates higher admission of insured individuals. Hausman test proves health insurance variable to be exogeneous and substantiates the positive impact of SSP on utilization of health services. Contrary to the findings on SEWA in Gujarat $[15,16]$, the findings of this study does support a positive impact of MHI on hospitalization as documented in other literature $[9,13,14]$. Certain design features such as availability of drugs in network hospitals, large network of hospitals and streamlined claim procedure did increase the utilization of health services. Given the similarities in the pattern of illness, higher proportion of hospitalization in insured group implies over-utilization. The results of the study did not show over-utilization, defined as the number of days spent in 
the hospital. This can be attributed to certain design features of SSP (strict monitoring by SSP assistants and preauthorization process) that curtailed moral hazard behaviour.

Another finding that draws attention is the horizontal equity in utilization, based on income and gender. SSP did achieve gender equity by enabling insured women utilize greater health services compared to their counterparts in uninsured groups (model 3b). However, SSP failed to provide vertical equity since women, who need greater health care, used less inpatient services than men in insured group. In this study, men or heads of the households take decisions related to access to health services and expenditure of the households. Usually, health needs of women are not prioritized [26]. In a similar manner, poorest insured individuals had better utilization compared to those in uninsured and newly insured groups (model 3a). On the contrary, vertical equity was lacking in view of lower admission from insured poorest class compared to better-off class within insured group. Indirect cost of treatment (transportation to hospitals in towns, lodging and loss of wages) might have prevented the poorest to utilize health services more than high-income individuals since majority of them live in rural areas. Most of the heads of these households worked as daily wage earners, hence losing a day's job would result in the loss of wage. Further, the poorest borrow even to pay the premium shows their precarious financial situation and supports our findings that SSP lacks vertical equity. However, claim benefits from SSP did reduce the financial burden of inpatient treatment for poorest individuals compared to those in uninsured/ newly insured group. These findings are to be interpreted keeping in mind the narrow definition of equity in this study; hence future research is warranted to assess vertical equity impact of MHI schemes.

The study findings suggest that SSP has achieved its primary goal of better utilization of health services at modern health facilities. This indicates a larger role for MHI in health financing arena to meet the goal of universal health coverage. Yet, it alone may have a limited role due to smaller risk pool and financial vulnerability. Specifically, sustainability of SSP is doubtful in the long run due to high claims ratio and declining risk pool/ premium collection. The main factor for high claims ratio is the technical design features of SSP. The exclusion of outpatient treatment would result in higher inpatient care. There are no deductibles, copayments or waiting period restrictions that remove any financial barrier to access care. Even the cashless system of payment to the providers eased the claim disbursal and management. Field staffs provide guidance to members to claim insurance benefits from SSP. Despite these advantages, members do not seek care to realize benefits from SSP (moral hazard) since hospitalization involves other expenses such as transportation and food in addition to the loss of wages due to absence from the work that are additional uncovered expenses. Therefore, we can assert that SSP promoted welfare by increasing utilization for the poor households but not over-utilization.

Financial sustainability can be improved by increasing the revenue collection or by curtailing the expenditure. As we know that the claim benefits and administrative expenses exhaust the premium collected, there is an urgent need to curb the claim benefits and cost of administration. The ongoing losses without external funding resulted in the bleeding of health insurance portfolio of public sector insurance companies. In the years to come, these companies would withdraw from micro insurance market that escalates the magnitude of iatrogenic poverty. Hence, remedial measures to curtail administrative cost, control fraudulent behaviour of members and providers of health care, external grants or corporate funding through corporate social responsibility are suggested. Supply side interventions in the form of standard treatment protocols, drug formularies and primary health care facilities are essential to increase financial protection. To enhance enrolment, the premium should be subsidized, benefit package has to be generous and adequate awareness has to be created to stall decline in the risk pool.

\section{CONCLUSION}

This study paves the way to enhance our understanding of the MHI impact on access, HSB and utilization of health services in India. In the context of impact of MHI in India, this study certainly elucidates the positive utilization by making health care affordable and accessible. It acts as a conduit for empowerment in health for the poorest and women. Yet, lack of external validity of this study suggests that similar analysis should be undertaken to derive a context relevant model of health financing.

Since the market mechanism or the government is well equipped to offer health insurance services to people in rural and informal sector, incorporating MHI as an effective health financing mechanism to provide universal coverage of insurance is advocated. Knowing that the poorest postpone care during illness due to financial barriers, policymakers should take up stewardship role and provide necessary impetus to develop MHI as an industry. When India, a land of villages, embarks on "Right to Health" act to provide access to health care for population at the bottom of the pyramid, MHI is a viable sustainable health care financing mechanism that needs serious consideration in public policy arena. In case of SSP, sustainability is a pressing issue that needs serious deliberation and policy action.

\section{CONFLICT OF INTEREST}

The author confirms that this article content has no conflict of interest.

\section{ACKNOWLEDGEMENTS}

Declared none.

\section{REFERENCES}

[1] World Health Report. Health Systems: Improving Performance. Geneva; WHO 2000.

[2] World Health Report. World Health Statistics 2009. Geneva; WHO 2009.

[3] Patel RK, Trivedi KN, Nayak SN, et al. Treatment seeking behaviour of peri-urban community of Chandkheda. Nat $\mathrm{J}$ Commun Med 2010; 1 (1): 35-6.

[4] Sudharsanam MB, Rotti SB. Factors determining treatment seeking behaviour for sick children in a fishermen community in Pondicherry. Ind J Comm Med 2007; 32: 71-2. 
[5] Peters D, Yazbeck A, Sharma R, et al. India, raising the sights: better health systems for india's poor, poor: findings, analysis, and options. Health, Nutrition, and Population Series. Washington, D.C.: The World Bank 2002.

[6] Iyer A, Sen G. Health sector changes and health equity in the 1990s in India. In: Roghuram S, Ed. Health and equity: technical report series 1.8. Bangalore: HIVOS 2000.

[7] Musau S. Community-Based Health Insurance: Experiences and Lessons Learned from East and Southern Africa, Partner-ships for Health Reform Project, Inc. Bethesda: Abt Associates 1999.

[8] Msuya JM, Jütting J, Asfaw A. Impacts of Community Health Insurance Schemes on Health Care Provision in Rural Tanzania. Discussion Papers on Development Policy No. 82. Bonn: Centre for Development Research 2004.

[9] Jutting J. Do community-based health insurance schemes improve poor people's access to health care? Evidence from rural Senegal. World Development 2003; 32: 273-88.

[10] Yip W, Wang H, Hsiao W. The Impact of Rural Mutual Health Care on Access to Care: Evaluation of a Social Experiment in Rural China. Working paper, Progress in Health Care Financing. Cambridge MA: Harvard University 2008.

[11] Musau S. Community-Based Health Insurance: Experiences and Lessons Learned from East and Southern Africa. Partner-ships for Health Reform Project. Bethesda: Abt Associates Inc. 1999.

[12] Dror DM, Soriano E, Sarol J, et al. Field based evidence of enhanced health care utilization among persons insured by Micro Health Insurance Units in Philippines. Health Policy 2005; 73(Pt 3): 263-71.

[13] Wagstaff A, Lidelow M, Jun GJ, et al. Extending health insurance to rural population: An impact evaluation of China's new cooperative medical scheme. J Health Econom 2008; 28(2009):119.

[13] Rao K, Waters H, Steinhardt L. et al. An experiment with community health funds in Afghanistan. Health Policy Planning 2009; 11. doi:10.1093/heapol/czp018

[15] Ranson K M. The impact of SEWA's medical insurance fund on hospital utilization and expenditure: Results of a household survey. Health, Nutrition, and Population Series. Washington, D.C.: The World Bank 2001.
[16] Gumber A. Hedging the health of the poor: The case for community financing in India. HNP discussion Paper Series. Washington, D.C.: The World Bank 2001.

[17] Liu G, Zhaob Z, Cai R, Yamada T, Yamadad T. Equity in health care access to assessing urban health insurance reform in China. Social Sci Med 2002; 55: 1779-94.

[18] Ekman B. The impact of health insurance on outpatient utilization and expenditure: evidence from one middle-income country using national household survey data. Health Research Policy and Systems 2007; 5: 6 doi:10.1186/1478-4505-5-6 Available from http://www.health-policy-systems.com/content/5/1/6

[19] Chankova S, Sulzbach S, Diop F. Impact of mutual health organizations: evidence from West Africa. Health Policy Planning 2008; 23(Pt 4): 264-76.

[20] Schneider P, Diop F. Synopsis of Results on the Impact of Community-Based Health Insurance on Financial Accessibility to Health Care in Rwanda. Partnership for Health Reform, Technical paper. Bethesda: Abt Associates 2001.

[21] Ahmed S, Adams A, Chodhary M, Bhuiya A. Changing healthseeking behaviour in Matlab, Bangladesh: do development interventions matter? Health Policy and Planning 2003; 18 (Pt 3): 306-15.

[22] Jowett M, Deolalikar A, Martinsson P. Health insurance and treatment seeking behaviour: evidence from a low-income country. Health Econom 2004; 13: 845-57.

[23] Jutting, J. Tine, J. Micro insurance schemes and health care provision in developing countries: An empirical analysis of the impact of mutual health insurance schemes in rural Senegal. ILO/ZEF-Project No. 7359 Project report: 5. Germany: Centre for Development Research (ZEF) 2000.

[24] Gotsadze G, Bennett S, Gzirishvili D. Health care-seeking behavior and out-of-pocket payments in Tbilisi, Georgia. Health Policy Planning 2005; 20 (Pt 4): 232-42.

[25] Aday L A, Andersen R. A framework for the study of access to medical care. Health Services Res 1974; 9(Pt 3): 208-20.

[26] Asfaw A, Lamanna F, Klasen S. Gender gap in parents' financing strategy for hospitalisation of their children: evidence from India. Health Econom 2010; 19(Pt 3): 265-79. 